\title{
Isolated Giant Primary Splenic Hydatid Cyst in a I0-Year-Old Boy: A Case Report
}

This article was published in the following Dove Press journal:

Pediatric Health, Medicine and Therapeutics

\author{
Saif Ghabisha' \\ Faisal Ahmed (1D) ${ }^{2}$ \\ Saleh Al-wageeh (1D' \\ Ebrahim Al-shami ${ }^{2}$ \\ Khalil Al-naggar $\mathbb{D}^{2}$ \\ Umayir Chowdhury $\mathbb{B}^{3}$ \\ Najm Haider ${ }^{2}$ \\ Fayed Al-yousofy ${ }^{4}$ \\ 'Department of General Surgery, Ibb \\ University of Medical Science, lbb, \\ Yemen; ${ }^{2}$ Urology Research Center, \\ Department of Urology, Al-Thora \\ General Hospital, lbb University of \\ Medical Science, Ibb, Yemen; ${ }^{3}$ Student \\ Research Committee, Shiraz University \\ of Medical Sciences, Shiraz, Iran; \\ ${ }^{4}$ Department of Pathology, Faculty of \\ Medicine, Taiz University of Medical \\ Science, Taiz, Yemen
}

Correspondence: Faisal Ahmed Al-Thora General Hospital, Alodine Street, lbb, Yemen

Email fmaaa2006@yahoo.com

\begin{abstract}
Hydatid cyst (HD) disease is a parasitic infection produced by cysts containing the larval stage of Echinococcus granulosus. It occurs worldwide, but its prevalence is higher in the rural communities of some developing countries like Yemen, where sheep and cattle raising constitute a crucial component of the agricultural industry. This zoonotic disease spreads due to close contact humans with sheep and dogs. The most involved organs with $\mathrm{HC}$ are the liver and lungs. However, other organs may also foster it, such as the spleen, with an incidence rate of between $0.5 \%$ and $6 \%$. To the best of our knowledge, primary involvement of the spleen by $\mathrm{HC}$ is very rare, and a few cases with isolated spleen $\mathrm{HC}$ in children were reported. In this study, a ten-year-old boy with a huge primary splenic HC is reported with chief chief complaint of pain and non-tender bulging in his abdomen's left upper quadrant. A $20 \times 16 \times 18 \mathrm{~cm}$ splenic cystic mass was detected by ultrasonography (US) and confirmed by abdominal computed tomography (CT) scan without macroscopic involvement in other organs. Total splenectomy was carried out for hem. Pathological examinations revealed cystic hydatidosis. We describe this case of an isolated huge spleen HC, which was successfully treated with total splenectomy, focusing on the management and outcome of this disease.
\end{abstract}

Keywords: case report, echinococcosis, hydatid cyst, primary, splenectomy

\section{Plain Language Summary}

Hydatid disease, a geographically widespread zoonosis, is commonly seen in most sheepraising countries in Asia, Africa, and other parts of the world. There are two types of parasites mainly involved in this disease, Cestodea (flatworms, tapeworms) and nematode (roundworms). The global incidence of primary splenic hydatidosis is rare. It occurs between $0.5 \%$ and $6 \%$ of patients and can be manifested both isolated or in concurrence with other hydatid diseases. We describe this case of a giant primary splenic HC in a ten-year-old boy who was brought to the clinic with complaints of pain and non-tender swelling in the left hypochondrium. Abdominal US and CT scan were performed to establish the diagnosis of a large splenic HC. There was no manifestation of any other organ or system involvement. The patient underwent a total splenectomy, and pathological examinations confirmed the cystic hydatidosis diagnosis. In conclusion, total splenectomy is the best choice for gaint $\mathrm{HC}$ to avoid complications and recurrence.

\section{Introduction}

Hydatid disease is a serious zoonotic disease and a substantial health risk in endemic areas. The larval stage of Echinococcus tapeworm causes the infection. Dogs are the primary host of this worm, and the intermediate hosts are sheep and cattle. ${ }^{1}$ Human 
acts as accidental intermediate hosts in the dog-sheep life cycle of this parasite. Hydatidosis can involve organs such as the liver (60-70\%), lungs (20\%) and infrequently in the thyroid, pancreas, kidneys, bone, breast, and spleen. ${ }^{2}$ While secondary splenic involvement is the third most common organ involvement, primary splenic $\mathrm{HC}$ has a rare incidence $(0.5-6 \%))^{3}$

Berlot was first to introduce Primary splenic hydatidosis in $1790 .^{4}$ Primary splenic infestation usually occurs when the parasite passes through the arterial route of two filters, hepatic and pulmonary. There were also reports of the retrograde venous route, which bypasses the arteria route. ${ }^{1}$ The primary manifestation of splenic hydatid disease is slowly growing asymptomatic cystic mass but might also present as painful bulging in the left hypochondrium. The patient may also present with dyspnea, anaphylactic responses caused by rupture of the cysts. ${ }^{5}$ The unusual location of $\mathrm{HC}$ may mislead physicians in differential diagnosis. ${ }^{4,6} \mathrm{HC}$ may present as a solitary or multiple cysts which each cyst can be multiloculated. US can reveal some specific signs such as daughter cyst, membrane detachment, and cyst wall calcification. Splenic HC presents itself as marginal or wrinkled eggshell like calcifications on x-rays. ${ }^{6}$

Farrokh and Singal were report primary splenic $\mathrm{HC}$ in children. Although splenic $\mathrm{HC}$ is a rare phenomenon, the authors suggest considering this diagnosis in spleen cystic lesion cases, especially in endemic areas. ${ }^{7,8}$ In this study,

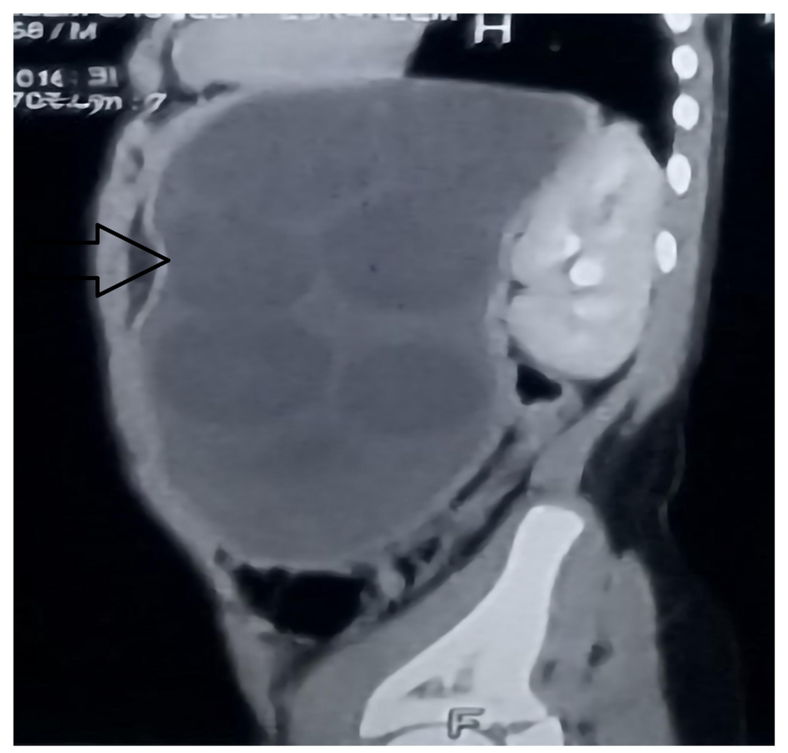

A we report a large primary splenic HC in a ten-year-old boy, rarely reported during childhood.

\section{Case Report}

The ethics committee of Ibb University of Medical Sciences approved this study. A ten-year-old boy came to our general surgery outpatient department of Al-Thora hospital, Ibb, Yemen, with a bulging in the left hypochondriac region. His father mentioned that the mass had started to overgrow over the last nine months. We took the family history and found that he lived in a village and owned a dog, which he keeps in the house, and he had no history of pica. On physical examination, the mass was occupying the left upper quadrant extending up to the umbilicus. The mass had limited horizontal mobility but moved with respiration. He had no other abdominal complaints. White blood cell was 2910 cell $/ \mathrm{mm}^{3}$, hemoglobin was $11.7 \mathrm{~g} / \mathrm{dl}$, and mild eosinophilia (7\%). Liver and kidney function test results were normal. The abdominopelvic US showed a $20 \mathrm{~cm}$ spleen cystic mass with several vasculatures compressing the left kidney.

In the left hypochondrium, xray showed a well-defined, rounded soft tissue opacity with some marginal calcification. The chest X-ray was normal. A large solitary $20 \times 16 \times 18 \mathrm{~cm}$ cystic mass in the spleen's hilum was detected in the abdominal ct-scan. It was sharply marginated and contained multiple round calcified peripheral daughter cysts (Figure 1). No other cystic lesion was detected in other organs such as the liver and peritoneum. Echinococcus latex hemagglutination

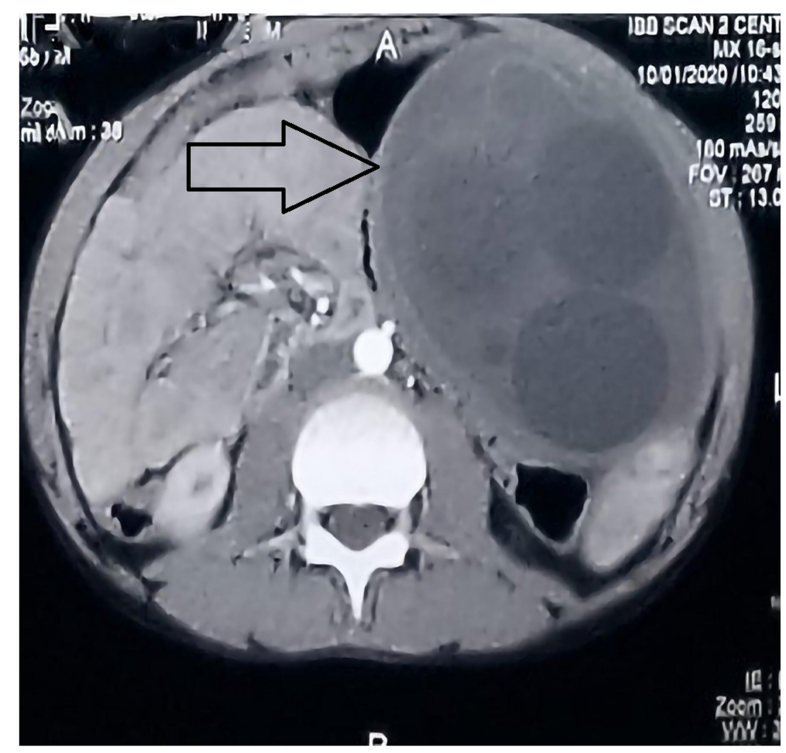

B

Figure I Axial (A) and sagittal (B) view of abdominal CT scan showing a calcified wall splenic hydatid cyst (arrow). 
test and indirect hemagglutination test were reported 1:6000 and 1:2200, respectively, which was positive. We made the diagnosis of a splenic $\mathrm{HC}$ based on imaging reports and hemagglutinations test results.

To perform laparotomy, via a midline incision, the abdominal cavity was explored, which revealed a large splenic cystic mass. The mass had adhesions to the diaphragm and displaced the left kidney and left adrenal posteriorly. The mass also pressurized the pancreas towards the right side and the stomach and the liver's left lobe anteriorly. The splenic hydatid cyst's fluid content was aspirated, and then $20 \%$ hypertonic saline was injected. After re-aspiration, we opened the cyst cavity and removed all endocysts. After this, we performed a splenectomy with the cyst (Figure 2). Using hypertonic saline ( $\mathrm{NaCl} 20 \%)$ abdominal cavity was washed to prevent any potential contamination induced infection. No blood transfusion was needed during surgery. Histopathological report described a laminated cyst with many scolices with a double layer of hooklets, a classic report of Echinococcus granulosus infection (Figure 3). The patient has a normal postoperative course in the hospital and was discharged on the 5 th day on albendazole $(6 \mathrm{mg} / \mathrm{kg}$ every twelve hours for three weeks). ${ }^{4}$ The patient also received prophylactic vaccination against Haemophilus influenza type b, Streptococcus pneumonia, and Neisseria meningitides one week after surgery. Abdominal CT scan follow-up at the sixth month after the surgery demonstrated the absence of recurrence.

\section{Discussion}

$\mathrm{HC}$ is a comonly found disease in farming communities, including the Middle East countries and the Republic of Yemen. ${ }^{9}$ Even in endemic areas, spleen $\mathrm{HC}$ is a rare phenomenon. Since the liver and lung act as first and second effective filters for most larvae, only $15 \%$ of cyst embryos can enter the systemic circulation to settle in other organs such as the spleen, mostly through arterial routes. For cyst embryos, another route to bypass the lung and liver is the portal and splenic veins. ${ }^{2}$

Primary splenic involvement is rare, but secondary involvement is common after the systemic dissemination via vessels or HC's local dissemination in the ruptured cyst. $^{3}$ In the pediatric population, the most involved organ is the lung. ${ }^{5}$

Physicians can easily get confused and neglect $\mathrm{HC}$ diagnosis when presented in an unusual organ. Pseudocyst, hematoma, abscess, and cystic neoplasms are considered as the primary differential diagnosis of splenic hydatidosis. Different types of splenic cystic lesions such as Splenic HC are mostly asymptomatic. ${ }^{10}$

Similarity in presentation and radiologic findings often makes preoperative diagnosis difficult. In $90 \%$ of cases using serological tests like ELISA, indirect hemagglutination test, and immunoelectrophoresis added with imaging findings can lead to successful splenic hydatidosis diagnosis. $^{11}$
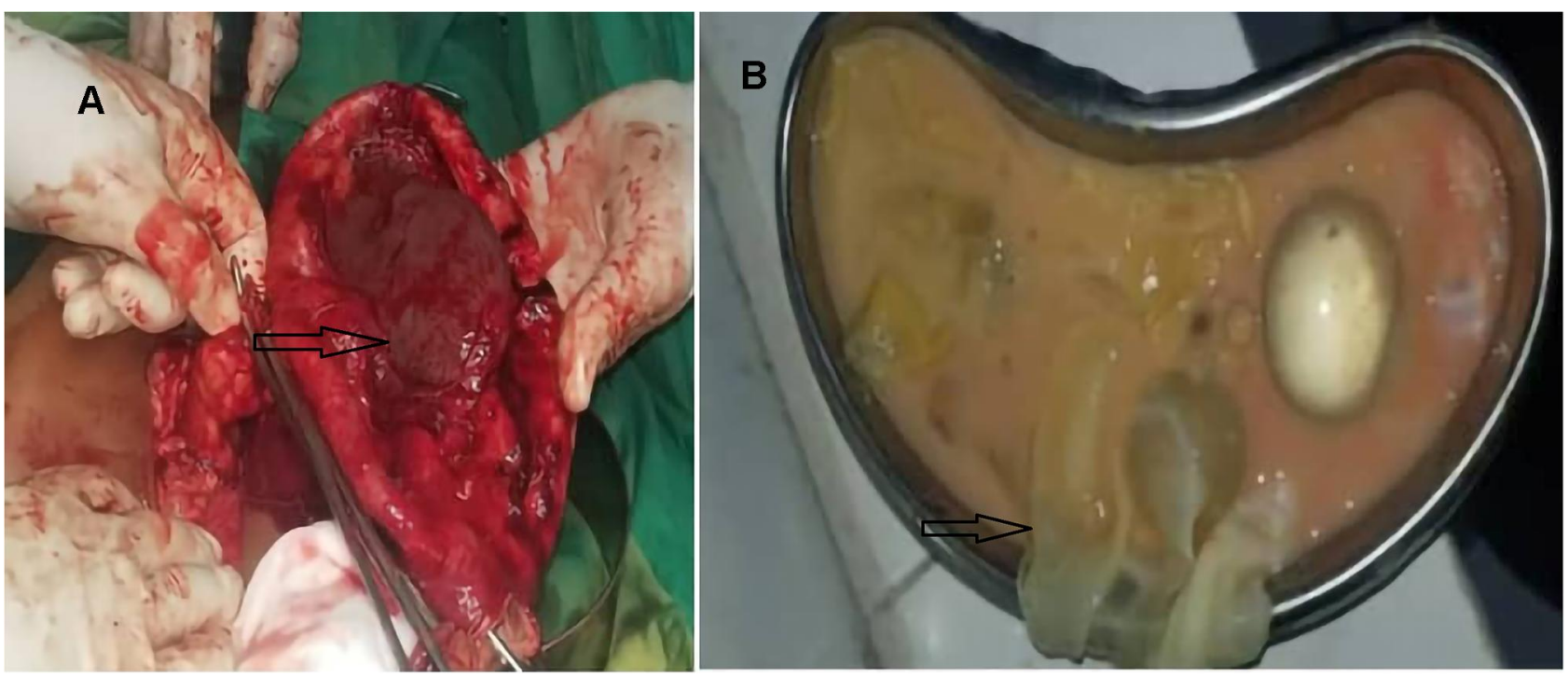

Figure 2 (A) Hydatid cyst within splenectomy specimen (arrow). (B) Hydatid cyst after removal. 


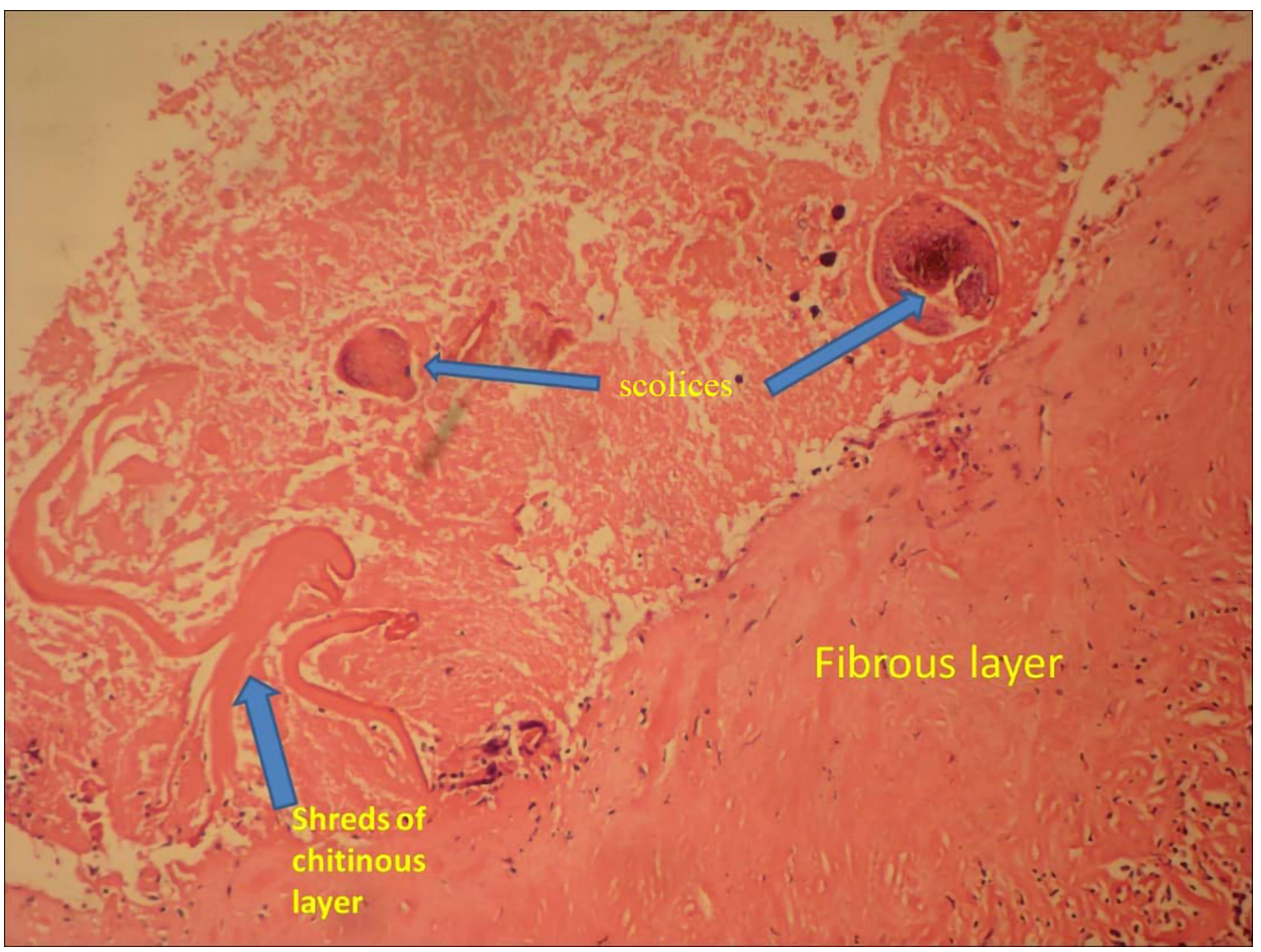

Figure 3 Histopathological specimen confirmed the hydatid cysts. The fibrous layer was named directly. Arrows showed shreds of the intermediate lamellar chitinous layer and the scolices in the inner layer.

Our patient was admitted to the inpatient department due to pain and a rapidly enlarging mass in the abdomen left upper quadrant area. Abdominal US and CT scan findings in the patient showed cyst wall calcification, daughter cysts, and membrane detachment, which is characteristic of $\mathrm{HC}$ findings. ${ }^{12}$ The size of isolated giant splenic $\mathrm{HC}$ was more than $20 \mathrm{~cm}$ in previous articles such as Pukar et al and Sarkari et al, which were similar to our report. ${ }^{4,12}$ Parasite-Human Immunologic relationships and the enveloping defensive structure around cysts are the main contributors to the growth of a HC.

Main surgical approaches to splenic hydatid disease are partial splenectomy, total splenectomy, cyst enucleation, removal with laparoscopy, and unroofing with omentoplasty. ${ }^{4,13}$ However, the standard management of giant $\mathrm{HC}$ is total or partial splenectomy for avoiding spontaneous or traumatic rupture. ${ }^{5}$ Partial splenectomy had an increased risk of bleeding when incising the splenic tissue, and unroofing the cyst wall had a risk of severe postoperative infection due to the residual space. Therefore, in case of multiple splenic cysts, total splenectomy is advised, especially when there are adhesions between the spleen and nearby organs. ${ }^{14}$

Due to the giant cyst size and its adhesion to surrounding tissues, we decide to drain the cyst. Before opening the cavities, aspiration of cyst fluid was done, and to kill daughter cysts, we inject and re-aspirated hypertonic saline $20 \%$ as a chemotherapy agent. ${ }^{5,6}$ Albendazole was administered as the main therapy is the postoperative and follow-up period. ${ }^{6}$

\section{Conclusions}

Primary splenic $\mathrm{HC}$ is rare. It presents mostly with a vague painful abdominal mass. US of the abdomen and CT scan are helpful to make the diagnosis. The approach and management must be individualized for each patient. In our patient, total splenectomy was the best choice to avoid complications and recurrence.

\section{Ethical Consideration}

This study was approved by the ethics committee of Ibb University of Medical Sciences. Written informed consent was obtained from the patient's parents for participation in our study.

\section{Funding}

There is no funding to report.

\section{Disclosure}

The authors declare that they have no conflicts of interest for this work. 


\section{References}

1. Shahriarirad R, Erfani A, Eskandarisani M, Rastegarian M, Sarkari B. Uncommon locations of cystic echinococcosis: a report of 46 cases from Southern Iran. Surg Res Pract. 2020;2020:2061045. doi:10.1155/ 2020/2061045

2. Malik AA, Ul Bari S, Younis M, Wani KA, Rather, AA. Primary splenic hydatidosis. Indian $J$ Gastroenterol. 2011;30:175-177. doi:10.1007/s12664-011-0104-x

3. Rasheed K, Zargar SA, Telwani AA. Hydatid cyst of spleen: a diagnostic challenge. $N$ Am J Med Sci. 2013;5:10-20. doi:10.4103/ 1947-2714.106184

4. Pukar MM, Pukar SM. Giant solitary hydatid cyst of spleen-a case report. Int J Surg Case Rep. 2013;4:435-437. doi:10.1016/j. ijscr.2012.12.019

5. Kalinova K, Stefanova P, Bosheva M. Surgery in children with hydatid disease of the spleen. $J$ Pediatr Surg. 2006;41:1264-1266. doi:10.1016/j.jpedsurg.2006.03.005

6. Culafić DM, Kerkez MD, Mijac DD, et al. Spleen cystic echinococcosis: clinical manifestations and treatment. Scand J Gastroenterol. 2010;45:186-190. doi:10.3109/00365520903428598

7. Farrokh D. Isolated primary splenic hydatid cyst in a six-year-old boy: a case report. Arch Clin Infect Dis. 2013;8. doi:10.5812/archcid.16996
8. Singal R, Sandhu KS, Mittal A, Gupta S, Jindal G. A giant splenic hydatid cyst. Proc (Bayl Univ Med Cent). 2016;29:55-57. doi:10.1080/08998280.2016.11929359

9. al-Hureibi AA, Amert A, al-Hureibi MA, Sharawee Z. Hepatic hydatid cysts: presentation and surgical management in Yemen. $J R$ Coll Surg Edinb. 1992;37:229-231.

10. Schlittler LA, Dallagasperina VW. Non-parasitic splenic cysts. Rev Col Bras Cir. 2010;37:442-446. doi:10.1590/S010069912010000600011

11. Aggarwal A, Sharma V. Primary splenic hydatidosis in a 25-year-old man: a case report. Cases J. 2009;2:8017. doi:10.4076/1757-16262-8017

12. Sarkari B, Fatemie Sfedan A, Moshfe A, et al. Clinical and molecular evaluation of a case of giant primary splenic hydatid cyst: a case report. Iran J Parasitol. 2016;11:585-590.

13. Arce MA, Limaylla H, Valcarcel M, Garcia HH, Santivañez SJ. Primary giant splenic echinococcal cyst treated by laparoscopy. Am J Trop Med Hyg. 2016;94:161-165. doi:10.4269/ajtmh.13-0505

14. Atmatzidis K, Papaziogas B, Mirelis C, Pavlidis T, Papaziogas T. Splenectomy versus spleen-preserving surgery for splenic echinococcosis. Dig Surg. 2003;20:527-531. doi:10.1159/000073689

\section{Publish your work in this journal}

Pediatric Health, Medicine and Therapeutics is an international, peerreviewed, open access journal publishing original research, reports, editorials, reviews and commentaries. All aspects of health maintenance, preventative measures and disease treatment interventions are addressed within the journal. Practitioners from all disciplines are invited to submit their work as well as healthcare researchers and patient support groups. The manuscript management system is completely online and includes a very quick and fair peer-review system. Visit http://www.dovepress.com/testimonials.php to read real quotes from published authors. 